\title{
Unusual applications of noninvasive ventilation
}

\author{
N. Ambrosino*\# and F. Guarracino"
}

ABSTRACT: The use of noninvasive ventilation (NIV) in acute hypercapnic respiratory failure, cardiogenic pulmonary oedema, acute lung injury/acute respiratory distress syndrome (ARDS), community-acquired pneumonia and weaning/post-extubation failure is considered common in clinical practice. Herein, we review the use of NIV in unusual conditions.

Evidence supports the use of NIV during fibreoptic bronchoscopy, especially with high risks of endotracheal intubation (ETI), such as in immunocompromised patients. During transoesophageal echocardiography as well as in interventional cardiology and pulmonology, NIV can reduce the need for deep sedation or general anaesthesia and prevent respiratory depression induced by deep sedation. NIV may be useful after surgery, including cardiac surgery, and, with a lower level of evidence, in patients with pulmonary contusion.

NIV should not be considered as an alternative to ETI in severe communicable airborne infections likely to progress to ARDS. NIV is being used increasingly as an alternative to ETI in end-stage symptomatic patients, especially to relieve dyspnoea. The role of assisted ventilation during exercise training in chronic obstructive pulmonary disease patients is still controversial.

NIV should be applied under close monitoring and ETI should be promptly available in the case of failure. A trained team, careful patient selection and optimal choice of devices, can optimise outcome of NIV.

KEYWORDS: Cardiac surgery, endoscopy, endotracheal intubation, interventional cardiology, interventional pulmonology, palliative care

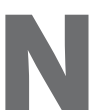
oninvasive ventilation (NIV) is one of the most important developments in respiratory medicine over the past 15 yrs $[1,2]$ and is increasingly used in many countries, but with a highly variable frequency of use [3]. A PubMed search from January 1966 to December 2010 using the term "noninvasive ventilation" gives 3,550 results, 678 of which are reviews. A recent study describing current mechanical ventilation practices found that, compared with 1998, in 2004 the use of NIV increased (11.1 versus $4.4 \%$ ) in 349 intensive care units (ICUs) in 23 countries [4]. Although continuous positive airway pressure (CPAP) is not considered as a form of ventilation since no inspiratory aid is applied, according to the International Consensus Conference 2001 [5], NIV is defined as any form of ventilatory support applied without endotracheal intubation (ETI). Strong evidence supports the use of NIV for acute respiratory failure (ARF) to prevent ETI, to facilitate extubation in patients with acute exacerbations of chronic obstructive pulmonary disease (COPD), and avoid ETI in acute cardiogenic pulmonary oedema and in immunocompromised patients. Weaker evidence supports the use of NIV for patients with ARF due to asthma exacerbations, or with post-operative or post-extubation ARF, pneumonia, acute lung injury (ALI), or acute respiratory distress syndrome (ARDS) [1, 2]. A recent survey asked physicians about only four "common" case scenarios of their own clinical experience with NIV: acute hypercapnic respiratory failure, cardiogenic pulmonary oedema, ALI/ARDS/community-acquired pneumonia/post-surgical (de novo) respiratory failure, and weaning/post-extubation failure [3]. Nevertheless, many other potential applications are undergoing investigation. This review will focus on recent developments in potential "unusual" application of NIV.

\section{DIAGNOSTIC MANOEUVRES \\ Fibreoptic bronchoscopy}

In hypoxaemic patients to be investigated for respiratory diseases, bronchoscopy may be mandatory but is potentially risky. $10-15 \%$ of the

\section{AFFILIATIONS}

*Pulmonary and Respiratory Intensive Care Unit,

"Intensive Care Unit, Cardio-Thoracic Dept, University Hospital Pisa, Pisa, and

${ }^{*}$ Weaning and Pulmonary Rehabilitation Unit, Auxilium Vitae, Volterra, Italy.

CORRESPONDENCE

N. Ambrosino

UO Pneumologia, Dipartimento Cardio-Toracico

Azienda Ospedaliero-Universitaria Pisana

Via Paradisa 2

Cisanello

56124 Pisa

Italy

Received:

Dec 142010

Accepted:

Jan 112011

First published online:

Feb 242011 
normal tracheal lumen may be occupied by the bronchoscope, potentially resulting in increased work of breathing (WOB), oxygen desaturation, respiratory complications and cardiac arrhythmias [6, 7]. Hypoxaemia is worsened by local anaesthetics or saline solution into the lower airways, and even more by performing bronchoalveolar lavage (BAL) [8]. Hypoxaemiaassociated cardiac arrhythmias (observed in $11-40 \%$ of patients undergoing bronchoscopy) are seldom clinically important. It has been reported that BAL performed in the ICU does not significantly increase ETI requirements in critically ill cancer patients with ARF, compared with noninvasive diagnostic testing, for identifying the cause of ARF in these patients [9]. Nevertheless, the American Thoracic Society (ATS) recommends avoiding flexible bronchoscopy and BAL in patients with arterial oxygen tension $\left(\mathrm{Pa}_{\mathrm{O}} \mathrm{O}_{2}\right)$ levels that cannot be corrected to $\geqslant 75 \mathrm{mmHg}$ or to an arterial oxygen saturation $>90 \%$ with supplemental oxygen [10]. In these higher risk patients, when noninvasive diagnostic tests are not conclusive, avoiding bronchoscopy means being compelled to use empirical treatment. As a consequence, when bronchoscopy is mandatory, only ETI and mechanical ventilation can assure adequate ventilation during the manoeuvre. Invasive mechanical ventilation is not risk-free. Most of the complications of invasive mechanical ventilation (table 1) are related to ETI, baro- or volutrauma, and the loss of airway defence mechanisms; some others may follow the extubation [11]. NIV may avoid most of these complications, especially ventilatoracquired pneumonia, while ensuring a similar level of ventilatory efficacy $[1,2,12]$.

Confirming a preliminary study [13], in a randomised controlled trial (RCT), mask CPAP reduced the risk of ARF following bronchoscopy in severely hypoxaemic patients [14].

TABLE 1 Complications of invasive mechanical ventilation

Related to tube insertion

Aspiration of gastric contents

Trauma of teeth, pharynx, oesophagus, larynx, trachea

Sinusitis (nasotracheal intubation)

Need for sedation

Related to mechanical ventilation

Arrhythmias, hypotension

Barotrauma

Related to tracheostomy

Haemorrhage

Trauma of trachea, oesophagus

False lumen intubation

Stomal infections, mediastinitis

Tracheomalacia, tracheal stenoses, granulation tissue formation

Tracheo-oesophageal or tracheoarterial fistulas

Caused by loss of airway defence mechanisms

Airway colonisation with Gram-negative bacteria

Pneumonia

Occurring after removal of the endotracheal tube

Hoarseness, sore throat, cough, sputum

Haemoptysis

Vocal cord dysfunction, laryngeal swelling

Reproduced from [1]
Another RCT in hypoxaemic patients showed that NIV increased the $\mathrm{Pa}_{2} \mathrm{O}_{2} /$ inspiratory oxygen fraction $\left(\mathrm{FI}, \mathrm{O}_{2}\right)$ ratio whereas the patients randomised to conventional oxygen therapy suffered from a worsening in oxygenation during bronchoscopy [15]. NIV-assisted bronchoscopy has also been reported to be useful in hypercapnic COPD patients with pneumonia [16]. Flexible bronchoscopy in spontaneously breathing young children was associated with significant decreases in tidal volume and respiratory flow that were reversed by CPAP [17]. In patients with acute exacerbation of COPD due to community-acquired pneumonia, who were candidates for ETI due to their hypercapnic encephalopathy and inability to clear copious secretions, NIV with early therapeutic bronchoscopy performed by an experienced team was considered a feasible, safe and effective strategy [18].

From these observations, the use of NIV during fibreoptic bronchoscopy is supported by evidence and should be considered for use, especially when risks of ETI are high, such as in immunocompromised patients. However, an expert team with skills in endoscopy and NIV should also be able to offer emergency intervention [1]. NIV during bronchoscopy may be performed by means of commercial or modified oronasal or full-face masks (fig. 1) [19].

\section{Transoesophageal echocardiography}

In orthopnoeic cardiac patients needing transoesophageal echocardiography (TEE), NIV can reduce the need for deep sedation or general anaesthesia. We recently reported the use of NIV-aided TEE under sedation in severely orthopnoeic patients with severe aortic valve stenosis [20]. NIV and continuous TEE were performed with the TEE probe passed through a modified face mask throughout percutaneous aortic valve implantation and aortic valvuloplasty procedures without technical problems, or respiratory or haemodynamic complications (fig. 2). NIV allowed performance of continuous TEE examination in lightly sedated patients, avoiding ETI and general anaesthesia.

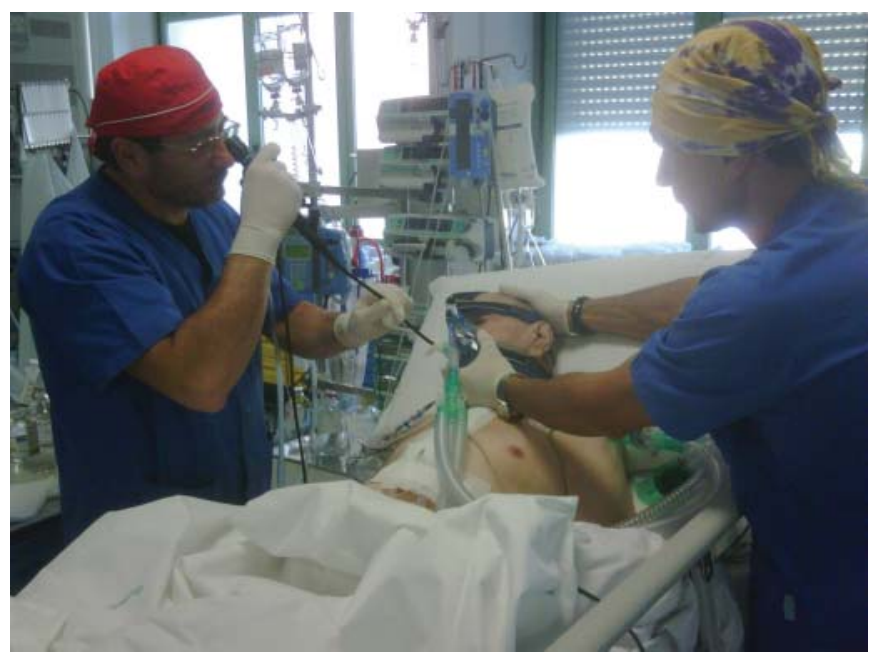

FIGURE 1. Use of noninvasive ventilation during bronchoscopy and bronchoalveolar lavage. The bronchoscope is introduced through a handmade hole in the mask. 


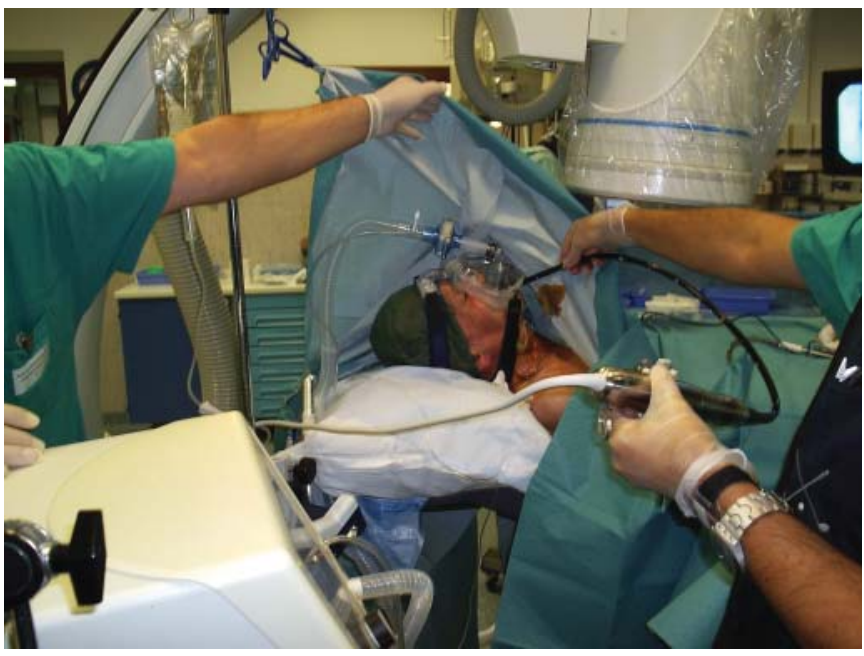

FIGURE 2. Noninvasive ventilation and continuous transoesophageal echocardiography (TEE) performed with the TEE probe passed through a modified face mask throughout percutaneous aortic valve implantation.

\section{MAJOR SURGERY}

\section{Abdominal and thoracic surgery}

Major abdominal and thoracic surgery may be fatally complicated early after surgery by ARF. Anaesthesia, site of surgery (e.g. upper abdomen surgery or surgical sites approaching the diaphragm) and pain may induce atelectasis and diaphragm dysfunction. Pulmonary atelectasis after major surgery is frequent in the dependent parts of the lungs of most anaesthetised patients (even more frequently in morbidly obese patients) [21] and may predispose patients to pneumonia. Atelectasis is associated with a reduction in lung compliance, hypoxaemia, increased pulmonary vascular resistance and possibly lung injury, potentially resulting in life-threatening ARF or at least delaying patient recovery. Maintenance of adequate oxygenation in the post-operative period is therefore mandatory [22]. NIV may be an important tool to prevent (prophylactic treatment) or treat (curative treatment) ARF avoiding ETI [23, 24]. The aims of NIV after surgery are: 1 ) to reduce the WOB; 2 ) to improve alveolar recruitment resulting in better gas exchange; and 3) to reduce left ventricular after-load, increasing cardiac output and improving haemodynamics [23, 24]. Evidence suggests that NIV, as a prophylactic or curative treatment, may be effective in reducing ETI rates, nosocomial infections, ICU and hospital lengths of stay, and morbidity and mortality in post-operative patients $[23,24]$. Both mask CPAP and positive pressure ventilation (PPV) have been used successfully in the post-operative period $[25,26]$.

Compared with standard treatment, noninvasive CPAP after major abdominal or thoracoabdominal aneurysm surgery improved hypoxaemia and reduced complications, such as pneumonia, atelectasis and the need for ETI [27, 28]. NIV substantially improved gas exchange and pulmonary function after gastroplasty in obese patients [29], and was also effective in patients with ARF and/or massive atelectasis after liver resection [30]. A case-control study reported that NIV for the treatment of post-oesophagectomy ARF may decrease the incidence of ETI and related complications, without increasing the risk of anastomotic leakage [31]. Preventive NIV use before
[32] or immediately after thoracic [33], cardiac [34] or vascular [28] surgery may reduce atelectasis. A prospective study evaluated early NIV use for ARF after lung resection during a 4-yr period in the setting of a medical and a surgical ICU of a university hospital [35]. Among 690 patients at risk of severe complications following lung resection, $16.3 \%$ experienced ARF, which was initially supported by NIV in $78.7 \%$, including $59(66.3 \%)$ patients with hypoxaemic and $30(33.7 \%)$ with hypercapnic ARF. The overall NIV success rate was $85.3 \%$ and in-ICU mortality was $6.7 \%$, whereas mortality rate following NIV failure was $46.1 \%$. Predictive factors of NIV failure were age, previous cardiac comorbidities, post-operative pneumonia, admission in the surgical ICU, no initial response to NIV and occurrence of noninfectious complications. Only two independent factors were significantly associated with NIV failure: cardiac comorbidities (OR 11.5) and no initial response to NIV (OR 11.7). Furthermore, NIV to treat early ARF after lung resection improved survival in one randomised study [36]. Current evidence shows that NIV associated with physiotherapy is safe and effective in reducing post-operative complications and improving patient recovery, thus enhancing the choice of available medical care and improving outcome in lung resection surgery [37, 38]. Although NIV has been successfully used after thoracic surgery, NIV fails in $\sim 20 \%$ of patients. In a study that aimed to assess possible risk factors for NIV failure in this condition, $20.3 \%$ of patients undergoing lung resection or pulmonary thromboendoarterectomy needed ICU admission and $29.6 \%$ of 135 patients undergoing NIV needed ETI [39]. Four independent variables were associated with NIV failure during the first $48 \mathrm{~h}$ : increased respiratory rate, increased Sequential Organ Failure Assessment (SOFA) score, number of fibreoptic bronchoscopies performed and number of hours spent on NIV. Nosocomial pneumonia was the leading cause of respiratory complications and occurred more in patients with NIV failure. Patients in the failure group also had a higher mortality rate [39]. NIV can also play an important role in preventing post-operative pulmonary complications in high-risk chronic ventilator users as a consequence of a restrictive lung pathology [40]. Other studies show that NIV has a role in ARF after solid organ transplantation (liver, lung and renal) [41, 42].

Despite the fact that few studies have examined different techniques to treat or prevent complications following various surgeries, NIV should be considered among the recommended options for post-surgical patients [1].

\section{Cardiac surgery}

NIV has also been used post-operatively in cardiac surgery patients. In 96 patients undergoing coronary artery revascularisation with mammary arteries [34], different modalities of NIV in the first 2 days after surgery were compared with the effect on lung function tests of conventional physiotherapy using incentive spirometry [38]. Patients were randomised to receive either noninvasive inspiratory pressure support (IPS) or CPAP for $1 \mathrm{~h}$ every $3 \mathrm{~h}$. A third group underwent incentive spirometry for $20 \mathrm{~min}$ every $2 \mathrm{~h}$. The use of CPAP and NIV was effective in decreasing the negative effect of coronary surgery on pulmonary function, as shown by a significant reduction of venous admixture and improved vital capacity, forced expiratory volume in $1 \mathrm{~s}$ and $\mathrm{Pa}_{2} \mathrm{O}_{2}$. In a randomised 
study of 150 patients following cardiac surgery, the noninvasive application of $5 \mathrm{cmH}_{2} \mathrm{O}$ positive external end-expiratory pressure (PEEP) plus $10 \mathrm{cmH}_{2} \mathrm{O}$ IPS for $30 \mathrm{~min}$ was superior to $5 \mathrm{cmH}_{2} \mathrm{O} \mathrm{CPAP}$ in improving pulmonary atelectasis, but did not confer any additional clinical benefit in terms of oxygenation, pulmonary function tests or ICU length of stay [43]. In 2009 , a prospective randomised study in 500 patients investigated the efficacy of prophylactic nasal $10 \mathrm{cmH}_{2} \mathrm{O} C P A P$ for $\geqslant 6 \mathrm{~h} \cdot$ day $^{-1}$ in preventing pulmonary complications after elective cardiac surgery in comparison with standard treatment [44]. In the study group, CPAP improved arterial oxygenation, reduced pulmonary complications (including pneumonia and re-intubation rate), and reduced re-admission rate to the ICU or intermediate care unit. In a more recent study, $35 \%$ of 2,261 spontaneously breathing post-cardiac surgery patients were diagnosed with ARF following primarily successful extubation [45]. Only $7 \%$ of patients did not tolerate NIV, whereas NIV was performed in $93 \%$. In patients with ARF, ejection fraction was lower, combined cardiac surgical procedures were more frequent, post-operative mechanical ventilation time was longer and the severity of illness score was higher. The duration of catecholamine support was longer and the transfusion rate was higher in the NIV group. Furthermore, mortality did not differ between patients with ARF treated by NIV and patients without ARF. Re-intubation after cardiac operations should be avoided, as noninvasive CPAP and PPV are safe and effectively improve arterial oxygenation in the majority of patients with nonhypercapnic oxygenation failure. However, it is of great importance to pay special care to sternal wound complications [46].

With negative pressure ventilation through cuirass, ponchowrap or iron-lung applicators, the chest wall is exposed to subatmospheric pressure during inspiration, resulting in airflow into the lungs through the mouth and nose. When the pressure around the chest wall returns to atmospheric, expiration occurs passively due to the elastic recoil of the lungs and chest wall. At the present time, there are five modes for delivering negative pressure ventilation: intermittent negative pressure ventilation (INPV), negative/positive pressure, continuous negative pressure (CNEP), negative pressure/CNEP and external high-frequency oscillation [47]. Modalities of negative pressure ventilation have been used either alone or in addition to PPV in cardiac surgery patients. A pilot study showed that CNEP attenuates the negative effects of PPV on cardiac output in these patients [48]. Prophylactic application of CNEP immediately after extubation decreased right ventricular load and improved arterial oxygenation in 16 infants and children managed in a paediatric ICU after surgery for congenital heart defects [1,49].

\section{THORACIC TRAUMA}

Pulmonary parenchymal contusion is the most frequent lesion, whereas flail chest is a rare finding in multiple trauma patients [50]. Since the 1980s, CPAP has been used to treat thoracic trauma. Nevertheless, ETI and mechanical ventilation are the treatments of choice for blunt chest trauma, a frequent injury in multiple trauma patients [51], with prolonged mechanical ventilation being mainly associated with bilateral chest injuries, increased age and severity of neurological damage [52].
Noninvasive CPAP and bilevel positive airway pressure have been increasingly applied in clinical practice for trauma patients. With the contribution of appropriate pain-management protocols, there has been a decrease in the incidence of ETI in blunt thoracic trauma [53]. In an uncontrolled study, 33 hypoxaemic, but not hypercapnic, trauma patients were treated with CPAP via a snug-fitting face mask. All patients had demonstrated prolonged hypoxaemia despite supplemental oxygen before CPAP. The therapeutic goal of a $\mathrm{Pa}_{1} \mathrm{O}_{2} / \mathrm{FI}_{1} \mathrm{O}_{2}$ ratio of $>300$ was achieved in 32 out of 33 patients. Only two $(6 \%)$ patients required ETI, but neither for hypercapnia [54]. In another study, NIV was evaluated in the treatment of multiple rib fractures in 69 patients randomly allocated to one of the following two treatments: 1) a CPAP mask combined with regional analgesia; or 2) ETI and mechanical ventilation with PEEP [55]. Clinical outcome was as follows: the mean duration of treatment, ICU and hospital length of stay, and complications were lower for the group with CPAP. Infections caused the difference in complications, primarily pneumonias, which occurred in $14 \%$ of the group with CPAP but in $48 \%$ of the ETI group [55].

On the basis of nonrandomised studies [56, 57], guidelines for NIV recommend (although with a low level of evidence) CPAP in patients with thoracic trauma who remain hypoxic despite regional anaesthesia $[2,58]$. More recently, in a single-centre $\mathrm{RCT}$, patients with a $\mathrm{Pa}_{2} \mathrm{O}_{2} / \mathrm{FI}, \mathrm{O}_{2}$ ratio of $<200$ for $>8 \mathrm{~h}$ under high-flow oxygen within the first $48 \mathrm{~h}$ after thoracic trauma were randomised to remain on a high-flow oxygen mask or receive NIV. The interface was selected on the basis of the associated injuries. Thoracic anaesthesia was universally supplied unless contraindicated. After 25 patients were enrolled in each group, the trial was prematurely stopped for efficacy because the ETI rate was much higher in controls than in NIV patients. NIV was considered the only variable independently related to ETI. Furthermore, hospital length of stay was shorter in NIV patients [59]. Although they have a low level of evidence, these studies indicate that NIV may represent a valuable alternative to ETI in patients with pulmonary contusion [60].

\section{MINIMALLY INVASIVE INTERVENTIONAL TECHNIQUES Interventional cardiology}

Recent advances in interventional techniques have made it possible to offer minimally invasive treatment of aortic valve stenosis to elderly patients who cannot undergo standard surgical treatment due to a compromised overall health status or severe comorbidities, such as pulmonary disease. In this condition, orthopnoea prevents a prolonged supine position. We have recently reported our initial experience with NIV in interventional cardiology to support patients with severe pulmonary disease undergoing percutaneous implantation of an aortic bioprosthesis for severe valve stenosis [61]. NIV was delivered using IPS plus PEEP modality under conscious sedation through an adult oronasal mask (fig. 2). NIV was started in the sitting position and maintained for $10 \mathrm{~min}$ to allow the patient to adapt to both the mask and the ventilatory modality. Thereafter, the patient was placed in the supine position under NIV, which was performed throughout the procedure and continued in the ICU. In our experience, NIV allowed us to avoid general anaesthesia, alleviate orthopnoea and prevent ARF [61]. 


\section{Interventional pulmonology}

VITACCA et al. [62] found that INPV using a poncho wrap may be useful in reducing apnoeas during laser therapy under general anaesthesia, thus reducing hypercapnia, related acidosis, and the need for oxygen supplementation and related hazard of combustion. In further studies, compared with spontaneous ventilation, INPV in paralysed patients during interventional rigid bronchoscopy reduced administration of opioids, shortened recovery time, prevented respiratory acidosis, excluded the need for manually assisted ventilation, reduced oxygen need and afforded optimal surgical conditions [63, 64].

Video-assisted thoracoscopic surgery is a minimally invasive technique allowing for intrathoracic surgery without formal thoracotomy and its accompanying complications [65]. This technique requires the exclusion of a lung from ventilation. In order to support one-lung spontaneous ventilation in a highrisk patient, we successfully used face mask IPS with regional anaesthesia [66]. Although these patients pose substantial challenges to the anaesthetist, based on this preliminary experience, we think that critically ill patients scheduled for palliative surgery can be successfully managed with the combination of minimally invasive surgical techniques, neuraxial block and NIV. Our unpublished experience combined with evidence from published case reports of the combination of NIV and regional anaesthesia techniques [67-71] suggests that even critically ill patients may successfully undergo major abdominal and thoracic surgery in this manner.

\section{PANDEMICS}

In the 1950s, INPV by iron lung increased survival during the poliomyelitis epidemic [72]. Nevertheless, during the following decades, INPV played only a minor role. Use of NIV for severe acute respiratory syndrome (SARS) and other airborne diseases leading to ARF has been debated. Indeed, there is concern over whether NIV should be considered a high-risk procedure in infectious diseases, such as tuberculosis or recent pandemics [73]. On the basis of a previous experience with SARS, in which some caregivers were contaminated when a patient underwent ETI after NIV failure, use of this technique was discouraged for patients with this disease [74]. A study observed a greater risk of developing SARS in physicians and nurses performing ETI (relative risk (RR) 13.29) and NIV (RR 2.33, which is lower than for ETI), whereas nurses caring for patients receiving high-frequency oscillatory ventilation did not appear at an increased risk (RR 0.74) compared with their respective reference cohorts [75]. However, subsequent studies from China reported no evidence of viral spread to caregivers under appropriate precautions [76-78].

During the more recent H1N1 influenza pandemic, although adverse effects were not reported [79, 80], NIV success rate was highly variable [81, 82]. A document endorsed by the European Respiratory Society (ERS) and the European Society of Intensive Care Medicine (ESICM) stated that NIV should not be considered as an alternative to ETI in ARF secondary to H1N1 infection that is likely to progress to ARDS [83]. According to this document, NIV might be considered to prevent further deterioration and the need for ETI in patients with mild-to-moderate hypercapnic or hypoxaemic ARF, and/ or distress due to cardiogenic pulmonary oedema, in the absence of pneumonia, multiple organ failure and refractory hypoxaemia. It can be also used to prevent post-extubation respiratory failure in patients with resolving ARDS secondary to $\mathrm{H} 1 \mathrm{~N} 1$ infection, preferentially when the patient is no longer contaminated [83].

Indeed, some clinicians consider this technique to be contraindicated in ARF due to communicable respiratory airborne diseases, unless used inside a negative-pressure isolation room with strict precautions. Recent reports have demonstrated that the use of different face masks for NIV may be associated with a substantial exposure to exhaled air, which occurs within a $1-\mathrm{m}$ radius from patients, with differences according to the type of mask, and enhanced with increased leakage from face masks, and with higher inspiratory pressures [84, 85]. Another study showed that NIV and chest physiotherapy are dropletgenerating procedures, producing droplets of $>10 \mu \mathrm{m}$ in size. Due to their large mass, most fall out on to local surfaces within $1 \mathrm{~m}$. These findings confirm that healthcare workers providing NIV and chest physiotherapy, and working within $1 \mathrm{~m}$ of an infected patient should have a higher level of respiratory protection, but that infection control measures designed to limit aerosol spread may have less relevance for these procedures [86]. The World Health Organization (WHO) has included NIV among aerosol-generating procedures in which the risk of pathogen transmission is possible [87]. However, as the procedure of ETI possesses a higher risk of disease transmission and associated complications, the use of NIV as initial ventilator support for ARF in the presence of highly transmissible diseases is a reasonable option under strict infection-control measures.

Technical issues should be considered in cases of ARF induced by contagious infectious diseases. Ventilators equipped with a double-line circuit without an expiratory port (i.e. whisper, plateau exhalation valve, anti-rebreathing valve etc.) should be preferred. This avoids the dispersion of expiratory air containing infected particles through the intentional leaks of a singleline circuit. A full-face or total-face mask should be preferred to a nasal mask in order to prevent the potential spreading of the contaminated exhaled air particles through unintentional mouth air leaks. Therefore, the choice of the brand and size that best fit the anatomy of the patient's face profile together with the delivery of adequate levels of pressures is crucial to minimise unintentional air leaks around the interface. Healthcare workers should be aware of the potential risks of caring for contagious patients during NIV application, and should take appropriate contact and droplet precaution. Specifically, clinicians should pay special attention during the phases of disconnection of the patient from the NIV: it is advisable to quickly switch the ventilators off as soon as the circuit is taken away from the mask to prevent the dispersion of the all-expiratory flow near the healthcare workers. In general, prudent isolation of the patient coupled with protective measures for care providers and other patients are the keys to limiting disease transmission (table 2) [83].

\section{PALLIATIVE AND END-OF-LIFE CARE}

As reported in a recent survey using a specifically designed questionnaire on the families' attitudes regarding care in the last 3 months of life of patients on home mechanical ventilation, the majority of patients complained of respiratory symptoms [88]. Symptom burden and palliative care needs of 


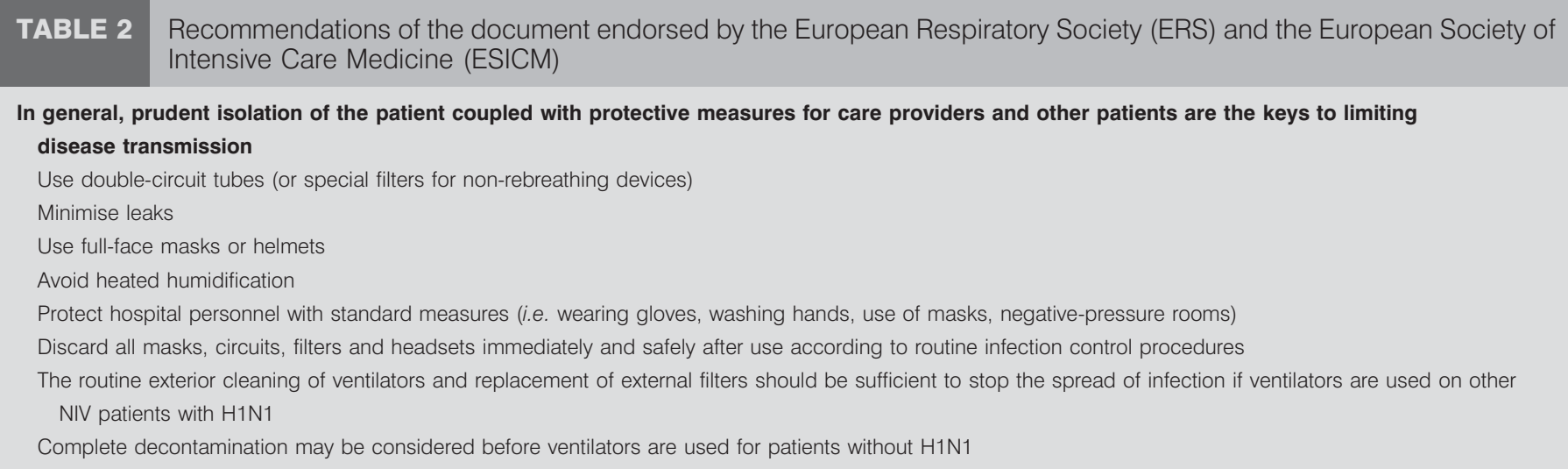

Information from [83]. NIV: noninvasive ventilation.

breathless patients with severe COPD are considerable and as high as among patients with advanced primary and secondary lung cancer, although patients with COPD have longer survival [89]. The goal of palliative care is to prevent and relieve suffering and to support the best possible quality of life for patients and their families, regardless of the stage of disease or the need for other therapies. Using these definitions, palliative care includes end-of-life care, but is broader and also includes care focused on improving quality of life and minimising symptoms like dyspnoea [90]. Patients with COPD are at risk of ARF and recent advances in NIV use raise questions about the use of this technology in the palliative care setting $[90,91]$. Despite the fact that some previous guidelines did not mention it [92], NIV is being used increasingly as an alternative to ETI in end-stage symptomatic patients, especially to relieve dyspnoea [93-97]. Therefore, more recent guidelines have incorporated such a notion with the limitation that: "As relief of dyspnoea with NIV may not relate to changes in arterial blood gases, it is appropriate to reassess the breathlessness experienced by patients receiving such ventilatory support at frequent intervals" [98]. A recent European survey in respiratory intermediate care units has shown that NIV was used as the extent of ventilatory care in almost a third of the patients [99]. A self-administered postal survey of all practicing intensivists, pulmonologists and respiratory therapists at 20 North American centres between 2003 and 2005 showed that for patients with do-not-intubate (DNI) orders, many physicians used NIV and many respiratory therapists were asked to initiate NIV, most often to treat COPD and cardiogenic pulmonary oedema [100]. Observational studies and clinical trials have recently underlined and confirmed the role of NIV as an effective alternative to ETI in those patients with chronic disease and poor life expectancy (with or without COPD), showing that this ventilatory technique may favourably reduce dyspnoea shortly after initiation even without an associated episode of hypercapnic ARF [101-103]. It was demonstrated that about half of the patients survived the episode of respiratory distress and were discharged from the hospital.

The Society of Critical Care Medicine has recently charged a task force with developing an approach for considering NIV use for patients who choose to forego ETI. The use of NIV for patients with ARF could be classified into three categories:
1) NIV as life support with no preset limitations on lifesustaining treatments; 2) NIV as life support when patients and families have decided to forego ETI; and 3) NIV as a palliative measure when patients and families have chosen to forego all life support, receiving comfort measures only. The task force suggested an approach to use NIV for patients and families who choose to forego ETI. NIV should be applied after careful discussion of the goals of care, with explicit parameters for success and failure, by experienced personnel and in appropriate healthcare settings [1, 104, 105].

The use of NIV in these extreme circumstances should take into account ethical, legal and religious issues. A Spanish study concluded that the use of NIV offers very low expectations of medium-term survival in DNI patients. The main reason may be that in a country with little experience in advanced directives, the DNI statement coincides with the final stages of disease progression [106].

\section{REHABILITATION}

In the most compromised COPD patients, extreme breathlessness and muscle fatigue limit training at the highest levels of exercise intensity prescribed by pulmonary rehabilitation programmes. Increased WOB also contributes to dyspnoea and exercise limitation [107]. In COPD patients, NIV during exercise reduces dyspnoea and increases exercise tolerance [108, 109] without relevant haemodynamic effects [110]. Inspiratory support provides symptomatic benefit by unloading the ventilatory muscles [111] and CPAP counterbalances the intrinsic PEEP [112, 113]. Nevertheless, the role of assisted ventilation during exercise training in COPD patients is still controversial [114-118]. More evidence is required to better define the role of ventilatory support in routine training sessions in COPD [119]. Furthermore, it has been reported that in chronic hypercapnic COPD under long-term ventilatory support, NIV can also be administered during walking, resulting in improved oxygenation, decreased dyspnoea and increased walking distance. Therefore, NIV during walking could prevent hypoxia-induced complications [120, 121]. Nocturnal NIV has been suggested as an addition to diurnal pulmonary rehabilitation in COPD patients [122, 123]. NIV has also been used as an aid to exercise in patients with a restrictive ventilatory pattern [124, 125]. 


\section{CONCLUSION}

Although NIV is a consolidated therapeutic tool in several respiratory conditions [1, 2], its potential usefulness is far from being completely elucidated. More RCTs are needed to confirm the promising results in the reviewed unusual applications and other conditions.

\section{STATEMENT OF INTEREST}

None declared.

\section{REFERENCES}

1 Ambrosino N, Vagheggini G. Noninvasive positive pressure ventilation in the acute care setting: where are we? Eur Respir J 2008; 31: 874-886.

2 Nava S, Hill N. Non-invasive ventilation in acute respiratory failure. Lancet 2009; 374: 250-259.

3 Crimi C, Noto A, Princi P, et al. A European survey of noninvasive ventilation practices. Eur Respir J 2010; 36: 362-369.

4 Esteban A, Ferguson ND, Meade MO, et al. Evolution of mechanical ventilation in response to clinical research. Am J Respir Crit Care Med 2008; 177: 170-177.

5 International Consensus Conference in Intensive Care Medicine: non-invasive positive pressure ventilation in acute respiratory failure. Am J Respir Crit Care Med 2001; 163: 283-291.

6 Murgu SD, Pecson J, Colt HG. Bronchoscopy during noninvasive ventilation: Indications and technique. Respir Care 2010; 55: 595-600.

7 Payne CB Jr, Goyal PC, Gupta SC. Effects of transoral and transnasal fiberoptic bronchoscopy on oxygenation and cardiac rhythm. Endoscopy 1986; 18: 1-3.

8 Katz AS, Michelson EL, Stawicki J, et al. Cardiac arrhythmias, frequency during fiberoptic bronchoscopy and correlation with hypoxemia. Arch Intern Med 1981; 141: 603-606.

9 Azoulay E, Mokart D, Lambert J, et al. Diagnostic strategy for hematology and oncology patients with acute respiratory failure: randomized controlled trial. Am J Respir Crit Care Med 2010; 182: 1038-1046.

10 Goldstein RA, Rohatgi PK, Bergofsky EH, et al. Clinical role of bronchoalveolar lavage in adults with pulmonary disease. Am Rev Respir Dis 1990; 142: 481-486.

11 Epstein SK. Complications associated with mechanical ventilation. In: Tobin MJ, ed. Principles and Practice of Mechanical Ventilation. 2nd Edn. New York, McGraw-Hill, 2006; pp. 877-902.

12 Girou E, Schortgen F, Delclaux C, et al. Association of noninvasive ventilation with nosocomial infections and survival in critically ill patients. JAMA 2000; 284: 2361-2367.

13 Antonelli M, Conti G, Riccioni L, et al. Noninvasive positivepressure ventilation via face mask during bronchoscopy with BAL in high-risk hypoxemic patients. Chest 1996; 110: 724-728.

14 Maitre B, Jaber S, Maggiore SM, et al. Continuous positive airway pressure during fiberoptic bronchoscopy in hypoxaemic patients. A randomized double-blind study using a new device. Am J Respir Crit Care Med 2000; 162: 1063-1067.

15 Antonelli M, Conti G, Rocco M, et al. Noninvasive positivepressure ventilation $v s$. conventional oxygen supplementation in hypoxemic patients undergoing diagnostic bronchoscopy. Chest 2002; 121: 1149-1154.

16 Da Conceicao M, Genco G, Favier JC, et al. Fiberoptic bronchoscopy during non-invasive positive-pressure ventilation in patients with chronic obstructive lung disease with hypoxemia and hypercapnea. Ann Fr Anesth Reanim 2000; 19: 231-236.

17 Trachsel D, Erb TO, Frei FJ, et al. Use of continuous positive airway pressure during flexible bronchoscopy in young children. Eur Respir J 2005; 26: 773-777.

18 Scala R, Naldi M, Maccari U. Early fiberoptic bronchoscopy during non-invasive ventilation in patients with decompensated chronic obstructive pulmonary disease due to communityacquired-pneumonia. Critical Care 2010; 14: R80.

19 Heunks LMA, de Bruin CJR, van der Hoeven JG, et al. Noninvasive mechanical ventilation for diagnostic bronchoscopy using a new face mask: an observational feasibility study. Intensive Care Med 2010; 36: 143-147.

20 Guarracino F, Cabrini L, Baldassarri R, et al. Non-invasive ventilation aided transoesophageal echocardiography in high risk patients: a pilot study. Eur J Echocard 2010; 11: 554-556.

21 Eichenberger AS, Proietti S, Wicky S, et al. Morbid obesity and postoperative pulmonary atelectasis: an underestimated problem. Anesth Analg 2002; 95: 1788-1792.

22 Duggan M, Kavanagh BP. Pulmonary atelectasis a pathogenic perioperative entity. Anesthesiology 2005; 102: 838-854.

23 Jaber S, Michelet $P$, Chanques G. Role of non-invasive ventilation (NIV) in the perioperative period. Best Pract Res Clin Anaesthesiol 2010; 24: 253-265.

24 Jaber S, Chanques G, Jung B. Postoperative noninvasive ventilation. Anesthesiology 2010; 112: 453-461.

25 Jaber S, Delay JM, Chanques G, et al. Outcomes of patients with acute respiratory failure after abdominal surgery treated with noninvasive positive pressure ventilation. Chest 2005; 128: 2688-2695.

26 Ferreyra GP, Baussano I, Squadrone V, et al. Continuous positive airway pressure for treatment of respiratory complications after abdominal surgery: a systematic review and meta-analysis. Ann Surg 2008; 247: 617-626.

27 Squadrone V, Coha M, Cerutti E, et al. Continuous positive airway pressure for treatment of postoperative hypoxemia. JAMA 2005; 293: 589-595.

28 Kindgen-Milles D, Muller E, Buhl R, et al. Nasal continuous positive airway pressure reduces pulmonary morbidity and length of stay following thoracoabdominal aortic surgery. Chest 2005; 128: 821-828.

29 Joris JL, Sottiaux TM, Chiche JD, et al. Effect of bi-level positive airway pressure nasal ventilation on the postoperative pulmonary restrictive syndrome in obese patients undergoing gastroplasty. Chest 1997; 111: 665-670.

30 Narita M, Tanizawa K, Chin K, et al. Noninvasive ventilation improves the outcome of pulmonary complications after liver resection. Intern Med 2010; 49: 1501-1507.

31 Michelet $\mathrm{P}, \mathrm{D}^{\prime}$ Journo $\mathrm{XB}$, Seinaye $\mathrm{F}$, et al. Non-invasive ventilation for treatment of postoperative respiratory failure after oesophagectomy. Br J Surg 2009; 96: 54-60.

32 Perrin C, Jullien V, Venissac N, et al. Prophylactic use of noninvasive ventilation in patients undergoing lung resectional surgery. Respir Med 2007; 101: 1572-1578.

33 Aguilo R, Togores B, Pons S, et al. Noninvasive ventilatory support after lung resectional surgery. Chest 1997; 112: 117-121.

34 Matte P, Jacquet L, Van Dick M, et al. Effects of conventional physiotherapy, continuous positive airway pressure and noninvasive ventilatory support with bilevel positive airway pressure after coronary artery bypass grafting. Acta Anaesthesiol Scand 2000; 44: 75-81.

35 Lefebvre A, Lorut C, Alifano M, et al. Noninvasive ventilation for acute respiratory failure after lung resection: an observational study. Intensive Care Med 2009; 35: 663-670.

36 Auriant I, Jallot A, Hervé P, et al. Noninvasive ventilation reduces mortality in acute respiratory failure following lung resection. Am J Respir Crit Care Med 2001; 164: 1231-1235.

37 Freynet A, Falcoz PE. Does non-invasive ventilation associated with chest physiotherapy improve outcome after lung resection? Interact CardioVasc Thor Surg 2008; 7: 1152-1154.

38 Ambrosino N, Gabbrielli L. Physiotherapy in the peri-operative period. Best Pract Res Clin Anaesthesiol 2010; 24: 283-289.

39 Riviere S, Monconduit J, Zarka V, et al. Failure of noninvasive ventilation after lung surgery: a comprehensive analysis of 
incidence and possible risk factors. Eur J Cardiothorac Surg 2010; [Epub ahead of print DOI: 10.1016/j.ejcts.2010.08.016].

40 Lumbierres M, Prats E, Farrero E, et al. Noninvasive positive pressure ventilation prevents postoperative pulmonary complications in chronic ventilators users. Respir Med 2007; 101: $62-68$.

41 Antonelli M, Conti G, Bufi M, et al. Noninvasive ventilation for treatment of acute respiratory failure in patients undergoing solid organ transplantation: a randomized trial. JAMA 2000; 283: 235-241.

42 Feltracco P, Serra E, Barbieri S, et al. Noninvasive ventilation in postoperative care of lung transplant recipients. Transplant Proc 2009; 41: 1339-1344.

43 Pasquina P, Merlani P, Granier J, et al. Continuous positive airway pressure versus noninvasive pressure support ventilation to treat atelectasis after cardiac surgery. Anesth Analg 2004; 99: 1001-1008.

44 Zarbock A, Mueller E, Netzer S, et al. Prophylactic nasal continuous positive airway pressure following cardiac surgery protects from postoperative pulmonary complications: A prospective, randomized, controlled trial in 500 patients. Chest 2009; 135: 1252-1259.

45 Kilger E, Möhnle P, Nassau K, et al. Noninvasive mechanical ventilation in patients with acute respiratory failure after cardiac surgery. Heart Surg Forum 2010; 13: E91-E95.

46 Boeken U, Schurr P, Kurt M, et al. Early reintubation after cardiac operations: impact of nasal continuous positive airway pressure (nCPAP) and noninvasive positive pressure ventilation (NPPV). Thorac Cardiovasc Surg 2010; 7: 398-402.

47 Corrado A, Gorini M. Negative pressure ventilation. In: Tobin MJ, ed: Principles and Practice of Mechanical Ventilation, 2nd Ed. New York, McGraw-Hill, 2006; pp 403-419.

48 Chaturvedi RK, Zidulka AA, Goldberg P, et al. Use of negative extrathoracic pressure to improve hemodynamics after cardiac surgery. Ann Thorac Surg 2008; 85: 1355-1360.

49 Shime $\mathrm{N}$, Toida $\mathrm{C}$, Itoi $\mathrm{T}$, et al. Continuous negative extrathoracic pressure in children after congenital heart surgery. Crit Care Resusc 2006; 8: 297-301.

50 Lucangelo U, Ferluga M. Trauma. In: Elliott M, Nava S, Schonhofer B, eds. Non-Invasive Ventilation and Weaning: Principles and Practice. London, Hodder Arnold, 2010; pp 454-458.

51 Cohn SM. Pulmonary contusion. J Trauma 1997; 42: 973-979.

52 Dimopoulou I, Anthi A, Lignos M, et al. Prediction of prolonged ventilatory support in blunt thoracic trauma patients. Intensive Care Med 2003; 29: 1101-1105.

53 Papadakos PJ, Karcz M, Lachmann B. Mechanical ventilation in trauma. Curr Opin Anaesthesiol 2010; 23: 228-232.

54 Hurst JM, DeHaven CB, Branson RD. Use of CPAP mask as the sole mode of ventilatory support in trauma patients with mild to moderate respiratory insufficiency. J Trauma 1985; 25: 1065-1068.

55 Bolliger CT, Van Eeden SF. Treatment of multiple rib fractures. Randomized controlled trial comparing ventilatory with non ventilatory management. Chest 1990; 97: 943-948.

56 Gregoretti C, Beltrame F, Lucangelo U, et al. Physiologic evaluation of non-invasive pressure-support ventilation in trauma patients with acute respiratory failure. Intensive Care Med 1998; 24: 785-790.

57 Beltrame F, Lucangelo U, Gregori D, et al. Noninvasive positive pressure ventilation in trauma patients with acute respiratory failure. Monadi Arch Chest Dis 1999; 54: 109-114.

58 British Thoracic Society Standards of Care Committee. Noninvasive ventilation in acute respiratory failure. Thorax 2002; 57 192-211.

59 Hernandez G, Fernandez R, Lopez-Reina P, et al. Noninvasive ventilation reduces intubation in chest trauma-related hypoxemia: a randomized clinical trial. Chest 2010; 137: 74-80.
60 Keenan SP, Mehta S. Noninvasive ventilation for patients presenting with acute respiratory failure: the randomised controlled trials. Respir Care 2009; 54: 116-124.

61 Guarracino F, Cabrini L, Baldassarri R, et al. Noninvasive ventilation for awake percutaneous aortic valve implantation in high-risk respiratory patients: a preliminary study. J Cardiothorac Vasc Anesth 2010; [Epub ahead of print DOI: 10.1053/j.jvca. 2010.06.032].

62 Vitacca M, Natalini G, Cavaliere S, et al. Breathing pattern and arterial blood gases during Nd-YAG laser photoresection of endobronchial lesions under general anesthesia: use of negative pressure ventilation. A preliminary study. Chest 1997; 111: 1466-1473.

63 Natalini G, Cavaliere S, Vitacca M, et al. Negative pressure ventilation vs spontaneous assisted ventilation during rigid bronchoscopy. A controlled randomized trial. Acta Anaesthesiol Scand 1998; 42: 1063-1069.

64 Natalini G, Cavaliere S, Seramondi V, et al. Negative pressure ventilation vs external high frequency oscillation during rigid bronchoscopy. A controlled randomized trial. Chest 2000; 118: $18-23$.

65 Georghiou GP, Stamler A, Sharoni E, et al. Video-assisted thoracoscopic pericardial window for diagnosis and management of pericardial effusions. Ann Thorac Surg 2005; 80: 607-610.

66 Guarracino F, Gemignani R, Pratesi G, et al. Awake palliative thoracic surgery in a high-risk patient: one-lung, non-invasive ventilation combined with epidural blockade. Anaesthesia 2008; 63: 761-763.

67 Ferrandière M, Hazouard E, Ayoub J, et al. Non-invasive ventilation corrects alveolar hypoventilation during spinal anesthesia. Can J Anaest 2006; 53: 404-408.

68 Iwama H. Application of nasal bi-level positive airway pressure to respiratory support during combined epidural propofol anaesthesia. J Clin Anaesthesiol 2002; 14: 24-33.

69 Duque-Gonzales P, Ferrando A, Garutti I, et al. Noninvasive positive pressure ventilation during surgery in a patient with exacerbated chronic obstructive pulmonary disease. Rev Esp Anesthesiol Reanim 2004; 51: 290-291.

70 Warren J, Sharma SK. Ventilatory support during neuraxial blockade using bilevel positive airway pressure in a patient with severe respiratory compromise. Anesth Analg 2006; 102: 910-911.

71 Bapat PP, Anderson JA, Bapat S, et al. Use of continuous positive airway pressure during spinal anaesthesia in a patient with severe chronic obstructive pulmonary disease. Anaesthesia 2006; 61: 1001-1003.

72 Hodes HL. Treatment of respiratory difficulty in poliomyelitis. In: Poliomyelitis: Papers and Discussion Presented at the Third International Poliomyelitis Conference. Philadelphia, Lippincott, 1955.

73 McCracken J. Should noninvasive ventilation be considered a highrisk procedure during an epidemic? CMAJ 2009; 181: 663-664.

74 Poutanen SM, Low DE, Henry B, et al. Identification of severe acute respiratory syndrome in Canada. N Engl J Med 2003; 348: 1195-2005.

75 Fowler RA, Guest CB, Lapinsky SE, et al. Transmission of severe acute respiratory syndrome during intubation and mechanical ventilation. Am J Respir Crit Care Med 2004; 169: 1198-1202.

76 Cheung TMT, Yam LYC, So LKY, et al. Effectiveness of noninvasive positive pressure ventilation in the treatment of acute respiratory failure in severe acute respiratory syndrome. Chest 2004; 126: 845-850.

77 Zhao Z, Zhang F, Xu M, et al. Description and clinical treatment of an early outbreak of severe acute respiratory syndrome (SARS) in Guangzhou, PR China. J Med Microbiol 2003; 52: 715-720.

78 Yam LYC, Chan AYF, Cheung TMT, et al. Noninvasive versus invasive mechanical ventilation for respiratory failure in severe acute respiratory syndrome. Chin Med J 2005; 118: 1413-1421. 
79 Djibré M, Berkane, Salengro A, et al. Non-invasive management of acute respiratory distress syndrome related to Influenza A (H1N1) virus pneumonia in a pregnant woman. Intensive Care Med 2010; 36: 373-374.

80 Winck JC, Marinho A. Non-invasive ventilation in acute respiratory failure related to 2009 pandemic Influenza A/ H1N1 virus infection. Crit Care 2010; 14: 408.

81 Bai L, Gu L, Cao B, et al. Clinical features of pneumonia caused by influenza A (H1N1) virus in Beijing, China. Chest 2011; 139: $1150-1164$.

82 Nin N, Soto L, Hurtado J, et al. Clinical characteristics and outcomes of patients with 2009 influenza A (H1N1) virus infection with respiratory failure requiring mechanical ventilation. J Crit Care 2011; 26: 186-192.

83 Conti G, Larrsson A, Nava S, et al. On the role of non-invasive ventilation (NIV) to treat patients during the H1N1 influenza pandemic. http://dev.ersnet.org/uploads/Document/63/WEB_ CHEMIN_5410_1258624143.pdf. Date last updated: November 2009.

84 Hui DS, Hall SD, Chan MTV, et al. Noninvasive positivepressure ventilation. An experimental model to assess air and particle dispersion. Chest 2006; 130: 730-740.

85 Hui DS, Chow BK, Ng SS, et al. Exhaled air dispersion distances during noninvasive ventilation via different Respironics face masks. Chest 2009; 136: 998-1005.

86 Simonds AK, Hanak A, Chatwin M, et al. Evaluation of droplet dispersion during non-invasive ventilation, oxygen therapy, nebuliser treatment and chest physiotherapy in clinical practice: implications for management of pandemic influenza and other airborne infections. Health Technol Assess 2010; 14: 131-172.

87 World Health Organization. Infection prevention and control during health care for confirmed, probable, or suspected cases of pandemic (H1N1) 2009 virus infection and influenza-like illnesses. www.who.int/csr/resources/publications/cp150_2009_ 1612_ipc_interim_guidance_h1n1.pdf Date last updated: December 16, 2009.

88 Vitacca M, Grassi M, Barbano L, et al. Last 3 months of life in home-ventilated patients: the family perception. Eur Respir J 2010; 35: 1064-1071.

89 Bausewein C, Booth S, Gysels M, et al. Understanding breathlessness: cross-sectional comparison of symptom burden and palliative care needs in chronic obstructive pulmonary disease and cancer. J Palliat Med 2010; 13: 1109-1118.

90 Curtis JR. Palliative and end-of-life care for patients with severe COPD. Eur Respir J 2008; 32: 796-803.

91 Clarke DE, Vaughan L, Raffin TA. Noninvasive positive pressure ventilation for patients with terminal respiratory failure: the ethical and economic cost of delaying the inevitable are too great. Am J Crit Care 1994; 3: 4-5.

92 Selecky PA, Eliasson CA, Hall RI, et al. Palliative and end-of-life care for patients with cardiopulmonary diseases: American College of Chest Physicians position statement. Chest 2005; 128 : 3599-3610.

93 Azoulay E, Alberti C, Bornstain C, et al. Improved survival in cancer patients requiring mechanical ventilatory support: impact of noninvasive mechanical ventilatory support. Crit Care Med 2001; 29: 519-525.

94 Levy M, Tanios MA, Nelson D, et al. Outcomes of patients with do-not-intubate orders treated with noninvasive ventilation. Crit Care Med 2004; 32: 2002-2007.

95 Schettino G, Altobelli N, Kacmarek RM. Noninvasive positive pressure ventilation reverses acute respiratory failure in selected "do-not-intubate" patients. Crit Care Med 2005; 33: 1976-1982.

96 Ambrosino N, Simonds A. The clinical management in extremely severe COPD. Respir Med 2007; 101: 1613-1624.

97 Clini EM, Ambrosino N. Nonpharmacological treatment and relief of symptoms in COPD. Eur Respir J 2008; 32: 218-228.
98 Mahler DA, Selecky PA, Harrod CG, et al. American College of Chest Physicians consensus statement on the management of dyspnea in patients with advanced lung or heart disease. Chest 2010; 137: 674-691.

99 Nava S, Sturani C, Hartl S, et al. End-of-life decision-making in respiratory intermediate care units: a European survey. Eur Respir J 2007; 30: 1156-1164.

100 Sinuff T, Cook DJ, Keenan SP, et al. Noninvasive ventilation for acute respiratory failure near the end of life. Crit Care Med 2008; 36: 789-794.

101 Bulow HH, Thorsager B. Non-invasive ventilation in do-notintubate patients: five-year follow-up on a two-year prospective, consecutive cohort study. Acta Anaesthesiol Scand 2009; 53: $1153-1157$.

102 Chu C-M, Chan VL, Wong IWY, et al. Noninvasive ventilation in patients with acute hypercapnic exacerbation of chronic obstructive pulmonary disease who refused endotracheal intubation. Crit Care Med 2004; 32: 372-377.

103 Cuomo A, Delmastro M, Ceriana P, et al. Noninvasive mechanical ventilation as a palliative treatment of acute respiratory failure in patients with end-stage solid cancer. Pall Med 2004; 18: 602-610.

104 Curtis JR, Cook DJ, Sinuff T, et al. Society of critical care medicine palliative noninvasive positive ventilation task force. Noninvasive positive pressure ventilation in critical and palliative care settings: understanding the goals of therapy. Crit Care Med 2007; 35: 932-939.

105 Truog RD, Campbell ML, Curtis JR, et al. Recommendations for end-of-life care in the intensive care unit: a consensus statement by the American College of Critical Care Medicine. Crit Care Med 2008; 36: 953-963.

106 Fernandez R, Baigorri F, Artigas A. Noninvasive ventilation in patients with "do-not-intubate" orders: medium-term efficacy depends critically on patient selection. Intensive Care Med 2007; 33: 350-354.

107 O'Donnell DE, Sanii R, Younes M. Improvement in exercise endurance in patients with chronic airflow limitation using continuous positive airway pressure. Am Rev Respir Dis 1988; 138: 1510-1514

108 Keilty SE, Ponte J, Fleming TA, et al. Effect of inspiratory pressure support on exercise tolerance and breathlessness in patients with severe stable chronic obstructive pulmonary disease. Thorax 1994; 49: 990-996.

109 Bianchi L, Foglio K, Pagani M, et al. Effects of proportional assist ventilation on exercise tolerance in COPD patients with chronic hypercapnia. Eur Respir J 1998; 11: 422-427.

110 Carrascossa CR, Oliveira CC, Borghi-Silva A, et al. Haemodynamic effects of proportional assist ventilation during highintensity exercise in patients with chronic obstructive pulmonary disease. Respirology 2010; 15: 1185-1191.

111 Borghi-Silva A, Oliveira CC, Carrascosa C, et al. Respiratory muscle unloading improves leg muscle oxygenation during exercise in patients with COPD. Thorax 2008; 63: 910-915.

112 Ambrosino N, Strambi S. New strategies to improve exercise tolerance in COPD. Eur Respir J 2004; 24: 313-322.

113 Ambrosino N, Palmiero G, Strambi S. New approaches in pulmonary rehabilitation. Clin Chest Med 2007; 28: 629-638.

114 Bianchi L, Foglio K, Porta R, et al. Lack of additional effect of adjunct of assisted ventilation to pulmonary rehabilitation in mild COPD patients. Respir Med 2002; 96: 359-367.

115 Hawkins P, Johnson LC, Nikoletou D, et al. Proportional assist ventilation as an aid to exercise training in severe chronic obstructive pulmonary disease. Thorax 2002; 57: 853-859.

116 Van t'Hul A, Gosselink R, Hollander P, et al. Training with inspiratory pressure support in patients with severe COPD. Eur Respir J 2006; 27: 65-72. 
117 Borghi-Silva A, Goncalves Mendes R, Toledo AC, et al. Adjuncts to physical training of patients with severe COPD: oxygen or noninvasive ventilation? Respir Care 2010; 55: 885-894.

118 Menadue C, Alison JA, Piper AJ, et al. Bilevel ventilation during exercise in acute on chronic respiratory failure: a preliminary study. Respir Med 2010; 104: 219-227.

119 Ambrosino N. Assisted ventilation as an aid to exercise training: a mechanical doping? Eur Respir J 2006; 27: 3-5.

120 Dreher M, Storre JH, Windisch W. Noninvasive ventilation during walking in patients with severe COPD: a randomised cross-over trial. Eur Respir J 2007; 29: 930-936.

121 Menadue C, Alison JA, Piper AJ, et al. Non-invasive ventilation during arm exercise and ground walking in patients with chronic hypercapnic respiratory failure. Respirology 2009; 14: 251-259.
122 Garrod R, Mikelsons C, Paul EA, et al. Randomized controlled trial of domiciliary non-invasive positive pressure ventilation and physical training in severe chronic obstructive pulmonary disease. Am J Respir Crit Care Med 2000; 162: 1335-1341.

123 Duiverman ML, Wempe JB, Bladder G, et al. Nocturnal noninvasive ventilation in addition to rehabilitation in hypercapnic patients with COPD. Thorax 2008; 63: 1052-1057.

124 Vila B, Servera E, Marín J, et al. Noninvasive ventilatory assistance during exercise for patients with kyphoscoliosis: a pilot study. Am J Phys Med Rehabil 2007; 86: 672-677.

125 Borel JC, Wuyam B, Chouri-Pontarollo N, et al. During exercise non-invasive ventilation in chronic restrictive respiratory failure. Respir Med 2008; 102: 711-719. 